\title{
An exploratory study of children's pretend play when using a switch-controlled assistive robot to manipulate toys
}

\section{Short title: Pretend play using assistive robots}

Kim D. Adams ${ }^{1,2}$, Adriana M. Rios Rincón ${ }^{3}$, Lina M. Becerra Puyo ${ }^{1}$, Javier L. Castellanos Cruz ${ }^{3,4}$, María F. Gómez Medina ${ }^{3,4}$, Al M. Cook ${ }^{1}$, Pedro Encarnação ${ }^{5}$

\section{Acknowledgments}

We would like to acknowledge Paola Esquivel and Isabela Sa for their assistance on this project. Parts of this study were presented at the Rehabilitation Engineering and Assistive Technology Society of North America (RESNA) 2015 Conference, in Denver, Colorado.

\section{Research Ethics}

This study was approved by the Health Research Ethics Board - Health Panel at the University of Alberta on October 18, 2013. Study ID: Pro00041696.

\section{Declaration of Conflicting Interest}

The authors declare that there is no conflict of interest.

\section{Funding}

This work was supported by the Women and Children's Health Research Institute (WCHRI).

\author{
Author Notes \\ ${ }^{1}$ Faculty of Rehabilitation Medicine, University of Alberta, Edmonton, Canada \\ ${ }^{2}$ Glenrose Rehabilitation Hospital, Edmonton, Canada \\ ${ }^{3}$ School of Medicine and Health Sciences, Universidad del Rosario, Bogotá, Colombia \\ ${ }^{4}$ Escuela Colombiana de Ingeniería Julio Garavito, Bogotá, Colombia \\ ${ }^{5}$ UCP - Católica Lisbon School of Business \& Economics, Lisbon, Portugal
}

\section{Corresponding author:}

Kim D. Adams, Faculty of Rehabilitation Medicine, 3-48 Corbett Hall, University of Alberta, Edmonton AB T6G 2G4 Email: kdadams@ualberta.ca 


\section{An exploratory study of children's pretend play when using a switch-controlled assistive robot to manipulate toys}

\section{Abstract}

Introduction: Children with disabilities may have difficulty accessing play due to limitations reaching and grasping. Assistive robots could be a means for children to manipulate toys and develop pretend play, and provide occupational therapists with a way to track children's play development.

Method: Experimental crossover trials were conducted to (a) establish if free-play set-ups without and with a robot would elicit a developmental sequence of play in typically developing children (b) determine if using a robot affected children's play, and (c) see what play schemes children performed to facilitate future development of play activities for children with disabilities. Thirty typically developing children between the ages of 3 and 7 played with conventional toys or unstructured materials without and with a switch-controlled Lego Mindstorms robot.

Results: Children demonstrated functional and pretend play at different levels of sophistication. Younger children did more functional play and older children did more pretend play. It was harder to exhibit pretend play when using the robot. Suggestions to support pretend play when children with disabilities use assistive robots are discussed.

Conclusion: Using assistive robots and appropriate play set-ups could provide a method to measure the play development level of children with disabilities and encourage pretend play.

\section{Keywords}

Assistive Robots, Assistive Technology, Pretend Play, Functional Play, Motor Impairments, Child Development 


\section{Introduction}

The World Health Organization (WHO, 2001), in its International Classification of Functioning and Disabilities version for Children and Youth (ICF_CY), considers play as one of the most important aspect of a child's life. Play is a fundamental right for all children and childhood's most important occupation (United Nations, 1999). Play contributes to children's development in terms of discovery, learning, mastery, adaptation, creativity, self-expression and social skills (Ferland, 2003).

Free play occurs when an activity is intrinsically motivated, spontaneous, self-regulated and actively engaging (Missiuna \& Pollock, 1991). When children perform free play, it provides them opportunities to explore objects, make decisions, discover and practice their skills, understand consequences of their actions (Missiuna \& Pollock, 1991), and to learn through creativity and problem solving (Henry, 2008).

A sequential development of play has been described by various authors among whom Piaget is one of the most influential (Piaget, 1951). Piaget proposed that play follows stages driven by cognitive development (Piaget, 1951). Sensory motor play begins in the first month and extends to around the age of two years. During the first year, play is pure assimilation -- i.e., a cognitive process in which children interpret their experience in light of current mental structures (Piaget, 1951). Symbolic play, occurring from around ages two to seven, is a complex type of play in which children develop the ability to represent knowledge, experience and objects symbolically (Piaget, 1951). Stagnitti and Unsworth (2004) classified symbolic play as a part of a broader category called pretend play. Pretend play has levels of sophistication that develop over childhood (Cohen, 2006; Piaget, 1951; Barton, 2010). From two to four years of age sensory motor play (or functional play) is still very common (Knox, 1974; Takata, 1974; Fein, 1981), but children begin to use real or miniature objects in pretend schemes and perform object substitution. As children develop and pretend play progresses, children imagine absent objects, for example drinking imaginary milk from a cup. Older children may take on roles and assign absent attributes to objects. An example is when a child pretends to be a veterinarian to fix their stuffed animals because the animals are sick. Between the ages of four and six, children begin to engage in more complex pretend play. At this time, children use familiar knowledge to construct novel situations during play. Role-playing is common, however functional play is still present on occasions (Knox, 1974; Takata, 1974). In this paper we will focus on functional and pretend play.

Play may be difficult for children with motor impairments due to limitations reaching and grasping (Rios, et al., 2016). Fewer opportunities to explore in play implies limited possibilities for interaction with the social and material environment, resulting in isolation, delays and detrimental effects on social, linguistic and cognitive development (Robins, et al., 2012; Klein, et al., 2011). Adults or playmates oftentimes manipulate the toys and become the directors of the play activity, leaving children with disabilities to be spectators rather than active participants (Blanche, 2008). Children's pretend play is related to the severity of their motor impairment (Pfeifer, et al., 2011). Children of the same age with Gross Motor Function Classification System (GMFCS) (Palisano, et al., 1997) levels I-III (i.e., able to walk or use a hand held mobility device) performed better during pretend play than children with GMFCS level V (i.e., transported in a manual chair by others). Occupational therapy interventions with children with disabilities should 
provide tools to the child and his or her family in order to increase the quality and frequency of the play experience in the child's daily living routines (Blanche, 2008).

Assistive robots have been used by children with disabilities to engage in play (Cook, et al., 2010). While children with disabilities played with a robot called the IROMEC in semistructured activities, they became the main protagonists of the play session (Robins, et al., 2012), and were equally active partners as their typically developing peers (Marti \& Iacono, 2011). Children with physical disabilities who operated a robot designed to manipulate Lego bricks, the PlayROB robot, engaged in autonomous play (Kronreif, et al., 2007). The level of playfulness of children with severe motor impairments significantly increased in free-play sessions with their mothers when they had access to a switch-controlled mobile Lego robot, compared to without it (Rios, et al., 2016). When playing with the robot, children were more intrinsically motivated, and they controlled the play as they chose the toys and play topics. The play observed was primarily functional, such as moving toys around the play area, but supporting children to also perform pretend play in free play situations is an important goal.

The age at which typically developing children exhibit the skills required to control mobile Lego robots using switches has been studied (Poletz, et al., 2010; Encarnação, et al., 2014).

Children three, four and five could demonstrate cause and effect (i.e., press and hold a switch to make the robot move). Four year olds were significantly more successful than three years olds and all five years olds were able to demonstrate inhibition (i.e., press a switch to move forward and release the switch to stop). Five year olds performed significantly better than four year olds, who in turn performed better than three year olds at demonstrating laterality and sequencing skills (i.e., press the appropriate switch to turn the robot in the desired direction, and then press the forward switch to knock over a stack of blocks).

Children with disabilities have controlled Lego robots through switches in various structured play activities (Cook, et al., 2011). Although it was not possible to administer standardized cognitive assessments for some of the children with disabilities, when the children performed the robot skills above (Poletz, et al., 2010; Encarnação, et al., 2014), the robot tasks provided a proxy measure of cognitive age, at least for these robot skills. For example, a 10 year old child with disabilities was able to demonstrate inhibition, thus his performance was comparable to a typically developing 4 or 5 year old (Cook, et al., 2011). It is possible that robotic play set-ups could also provide a proxy measure of play development level in children with disabilities.

The purpose of this study was to develop robotic free-play set-ups and test them with typically developing children as a first step towards developing a proxy measure of the play level of children with disabilities, and to observe the children's play to inform future development of play activities for children with disabilities.

The specific research questions were:

1. Is there a trend for pretend play to increase with children's age without and with the robot in the developed play set-ups?

2. What is the effect of the robot on pretend and functional play within each age group?

3. What play schemes do children perform without and with the robot? 


\section{Methods}

Ethical approval was obtained from the $<$ blinded name $>$ Health Research Ethics Board. An experimental crossover trial was conducted to explore the research questions.

\section{Participants}

A convenience sample of 30 typically developing children 3 to 7 years old was recruited from local schools and daycares. Exclusion criteria included any known diagnosis of neurological or physical disorder. There were seven 3 year olds $(M=42.42$ months, $\mathrm{SD}=3.45)$, five 4 year olds $(\mathrm{M}=50.6$ months, $\mathrm{SD}=3.13)$, six 5 year olds $(\mathrm{M}=64.83$ months, $\mathrm{SD}=3.76)$, five 6 year olds $(\mathrm{M}=76.8$ months, $\mathrm{SD}=4.02)$ and seven 7 year olds $(\mathrm{M}=92.71$ months, $\mathrm{SD}=4.5)$. One child was 8 years and a few days old, but he was located in the 7 year olds group.

\section{Materials}

The Lego Mindstorms EV3 was assembled as a car-like vehicle with a gripper for manipulation. The program to control the robot was written in National Instruments LabView on a PC. The PC sent commands to the robot via a BlueTooth dongle. The robot was controlled by six Ablenet Jelly Bean switches connected to the PC via a Don Johnston Switch Interface Pro 6.0 which made the robot go forward, backward, turn right or turn left as well as open and close a gripper, only while the switches were pressed.

Two sets of toys were used in this study: conventional toys and unstructured materials. The conventional toys were commercially available toys and included: animals (lion, elephant, bear, and zebra), fake food (a bottle of pop, bananas and corn), a boy doll and a girl doll, a fence made of Lego pieces and a truck. The unstructured materials, defined as junk play materials or inanimate objects, were: one shoe box, one tin, one dowel stick, two flat stick, three pebbles, one plastic cone, and a fence made out of Lego pieces. These conventional toys and unstructured materials were selected taking account that they were gender neutral (Stagnitti, et al., 1997) and had been included in the Child-Initiated Pretend Play Assessment (CHIPPA) (Stagnitti \& \& Unsworth, 2004). For the robot conditions, a wall of transparent Plexiglas restricted children from manipulating the toys using their hands. The play set-ups for conventional toys and unstructured materials are shown in Figure 1.

----- Insert Figure 1 about here -----

\section{Procedure}

All sessions took place in a laboratory setting, and were videotaped for post-session analysis. Parents were present for the session, and they were instructed not to prompt the child but to feel free to make the child feel comfortable.

The sessions included three parts. The first part involved tasks to allow the children to become familiar with the robot and the switches. Children knocked over blocks to practice with the aforementioned robot skills (cause and effect, inhibition, laterality, and sequencing) according 
to the protocol described in (Poletz et al., 2010). Part 2, not described here, was a problem solving task using the robot performed on the same day. Part 3, for play, was performed on the same day, unless the child was tired in which case he/she was seen a week later. Participants had no previous experience using a switch controlled robot.

The play part of the session began with reinforcing the robot skills and teaching the children how to use the robot and the gripper to push and grasp toys. Next, each child performed four trials, with two toy conditions (conventional or unstructured materials) and two manipulation mode conditions (without robot or with robot). The order of the conditions was randomly assigned. The toys (conventional or unstructured materials) were placed in the same locations in the play area at the beginning of each trial, as shown in Figure 1. The child was told, "You can play with all of the toys and you can do whatever you want with them". The children played with the toys using the randomly chosen manipulation mode, without robot (direct manipulation with hands) or with robot. Children 5 years and older played for 5 minutes in each trial, while 3 and 4 year olds played for 3 minutes as suggested in the CHIPPA (Stagnitti \& Unsworth, 2004). In the robot conditions, the Plexiglass was set-up beforehand, and the child was told that he could ask the investigator for help picking up or moving an object with the robot (e.g., nudging the robot or toy or placing a toy in the gripper). An investigator remained with the child and asked questions to clarify what the play activities were (e.g., "What is it happening?"), without providing any play suggestions.

If the child did not naturally exhibit any pretend play in the robot conditions during the first 5 (or 3) minute trial, the investigator then asked to take a turn pressing the switches to make the robot move. With unstructured materials the investigator pretended that the robot was taking a drink of water from the cup and then going to sleep in the box. With the conventional toys the investigator pretended the robot was feeding the animals and then taking an animal for a walk. After modeling, the trial proceeded as above and the child played for an additional 5 (or 3 ) minutes.

\section{Data Collection and Analysis}

A method to code the types of play was created, based on Barton (2010) and McCune-Nicolich (1981). The types of play codes were: no play (0), functional play with a sub-type of "with one object" (1.1) or "with two or more objects" (1.2), or pretend play with a sub-type of "functional play with pretense" (2.1), "with verbal confirmation" (2.2), "with object substitution" (2.3), "with imagining absent objects" (2.4), or "with assigning absent attributes" (2.5). Detailed descriptions and examples of the codes can be seen in Supplementary File 1.

The videos were observed in 15-second intervals. Each act performed by the child was called a play scheme e.g. moving toys from one location to another, pretending to be eating, etc. (McCuneNicolich, 1981). The type of play during the play scheme was coded. If, in the 15-second interval after the rater had coded a play type, the child continued doing the same play scheme, it was marked as a continuation (and not an additional count). If the child or the toys were out of the camera view, the corresponding interval was not scored. The type of play (i.e., no play, functional play or pretend play) exhibited by the child could not overlap; however, the different sub-types of pretend play could overlap during a play scheme. For example the child could perform an object 
substitution and at the same time imagine an absent object (in this case the highest score was chosen as the final code).

Two research assistants coded the videos, and their results were compared point by point. Agreement on all the sub-types of play was low (37\% agreement) but agreement on the three main type of play (i.e., no play, functional and pretend play) was high (85\%). The results presented here are based on calculations using the three main types of play only.

Both the diversity of the play types, and the duration of time spent in each play type were examined. Diversity was examined by counting the number of times the child performed each type of play (no, functional and pretend). A relative percentage was computed by dividing the number of play schemes of each type of play by the total number of play schemes in the trial. To examine the duration spent in each type of play, the number of 15 seconds intervals in which the child was engaged in a play type was counted and then divided by the total number of intervals in order to get a percentage. See Supplementary File 2 for sample data and calculations.

Results were graphed for all four conditions in terms of diversity and duration. Statistical comparisons were made between age groups (research question 1) and within age groups (research question 2) using SPSS (IBM, Chicago, USA), testing the results of play when the children were using conventional and unstructured toys without and with the robot (before modeling), having a confidence level of $95 \%$. For question 1, a one way independent ANOVA with linear contrast was used when the data was normally distributed and had homogeneous variances, and the JonckheereTerpstra test was used when the ANOVA assumptions were violated (Sheskin, 2000). For question 2 , multiple pair comparisons between no robot and robot were conducted for each age group, using a paired-samples t-test when the data was normally distributed, and the Wilcoxon signed-rank test was used when this assumption was violated. Since pretend and functional play were not strictly inversely proportional due to the occurrence of "no play", statistics were performed for both pretend and functional play types. The results obtained for the robot conditions after modeling were not statistically analyzed because not all children needed modeling.

Each play scheme performed by the child was documented during the coding process above. Play schemes that were performed by two or more children were graphed. On occasions children switched from one play scheme to another; therefore, multiple play schemes were recorded for some children. The play schemes after modeling were not graphed, but novel schemes were noted.

\section{Results}

\section{Trends in play with respect to age}

Figure 2 shows the means and standard deviations for each age group in terms of diversity for all conditions. Trends which were significant are marked with an asterisk. Duration data had no trends, and is presented in Supplementary File 3. Graphed data of each participant are presented in Supplementary Files 4 and 5. Detailed results of statistical analysis are provided in Supplementary File 6. 
----- Insert Figure 2 about here -----

Conventional toys. In terms of diversity, the ANOVA with linear contrast revealed a significant linear trend for pretend play with the robot $(p=0.015)$, indicating that the percentages increased with age. The Jonckheere test revealed a significant trend for functional play with the robot $(p=0.046)$, which indicated that it decreased with age. No additional significant trends were found.

Unstructured materials. One of the six year old children requested to stop the session because he was tired, so his scores were excluded from the relevant tests. In terms of diversity, the Jonckheere-Terpstra test revealed a significant trend for pretend play without $(p=0.002)$ and with the robot $(p=0.027)$, the amount of pretend play increased with age. The ANOVA with linear contrast showed that functional play without the robot had a significant trend $(p=0.000)$, which decreased with age. In terms of duration, the tests did not reveal any significant trends.

\section{Effect of the robot on play}

The averaged differences between using the robot or not for each age group are shown in Table 1 for pretend and functional play (calculated as the percentage in the robot condition minus the percentage in the no robot condition). Positive values mean that the percentages of a given type of play increased in the robot condition compared to the without robot condition, while negative values mean the percentages decreased. The differences that were significant are marked with an asterisk in Table 1. The number of children who required modeling is also shown in Table 1, along with the averaged differences between after and before modeling. Raw data for each participant can be found in Supplementary File 7.

----- Insert Table 1 about here -----

Conventional toys. In terms of diversity, the 3 year olds' pretend play was significantly less with the robot than without it ( $p=0.001)$ as was the 4 year olds' $(p=0.043)$. Functional play was significantly greater ( 3 year olds: $p=0.003$ and 4 year olds: $p=0.043$ ) when they performed with the robot than without it. The results in terms of duration revealed that the 3 and 6 year olds spent significantly less time engaged in pretend play with the robot than without it ( 3 year olds $p=0.001$ and 6 year olds $p=0.043$ ), and they spent more time in functional play with the robot than without it ( 3 year olds: $p=0.000$ and 6 year olds: $p=0.043$ ). There were no significant differences in the other age groups.

Unstructured materials. In terms of diversity, only the 3 year olds performed significantly less pretend play with the robot than without it $(p=0.043)$. In terms of duration, only the 3 year olds performed significantly less pretend play with the robot than without it $(p=0.002)$, and significantly more functional play with the robot than without it $(p=0.000)$.

\section{Play schemes}

Figure 3(a) and (b) show the play schemes that children elaborated using conventional toys without and with a robot and Figure 3(c) and (d) show the play schemes with unstructured 
materials without and with the robot. The novel schemes after modeling were: eight children pretended that the robot was hungry, angry or happy and four children pretended that the robot was eating, parking, exercising or collecting garbage.

---- Insert Figure 3 about here ----

\section{Discussion}

The first research question examined if there would be a trend for pretend play to increase according to age in the play set-ups. Some significant trends were seen when looking at diversity of play, but not for duration of play.

When children used their hands to manipulate there was no trend with the conventional toys. It was expected that younger children would do more functional play than the older children. However, it can be easier for children to participate in imaginative play with toy groups that have an obvious scheme (Stagnitti, et al., 1997). In our study, the conventional toys had a zoo scheme, which could account for why younger children accomplished similar amounts of pretend play as older children.

The unstructured materials did elicit a trend where younger children performed more functional play and older children performed more pretend play when children used their hands to manipulate. Unstructured materials require children to do object substitution for pretend play, which is a complex level of pretend play (Barton, 2010). Pretend play increases in complexity as children develop (Stagnitti \& \& Unsworth, 2004); thus, it was not expected to observe a great deal of pretend play with unstructured materials in the youngest children, whereas it was expected that older children would be able to incorporate unstructured materials in their pretend play as the objects do not limit their imagination and creativity. The results of this study confirmed this expectation.

When using the robot to manipulate the toys, there was a trend with younger children performing less pretend play and older children performing more pretend play for both conventional toys and unstructured materials. For the unstructured materials, statistical analysis did not show the opposite trend for functional play. Visual analysis of figure 2(d) shows nonoverlapping pretend and functional data for 3 and 4 year olds, but the older children had a wide range of functional play. It is possible that children were exploring the robot because it was a novel object. Functional play serves as a means to explore new objects not only in children but also in adults and even in animals (Burghardt, 2005; Piaget, 1951). The trend with conventional toys with the robot, but not when directly manipulating toys implies that the robot was imposing a challenge for younger children to exhibit pretend play.

The second research question examined the effect of the robot on children's play in each age group. The 3 year olds' pretend play diversity and duration for both types of toys was significantly affected when the robot was introduced. In addition, four year olds' pretend play was affected in terms of diversity with conventional toys when the robot was introduced. For both age groups, pretend play decreased and functional play increased. It is more cognitively demanding for children to manipulate toys using switches and a robot than to do direct manipulation (Alvarez, 2014). Also, it is possible that 3 and 4 year olds were performing functional play with the robot to 
explore it and how it related to the environment and themselves. This would be expected according Piaget (1951) and the Optimal Arousal Theory (Burghardt, 2005) where an early stage of play is present when an individual explores objects and settings that are not familiar. The 3-minute time frame for 3 and 4 year olds might not have been enough time for children to move from exploration of the robot properties towards more complex levels of play. There was also less pretend play and more functional play, in terms of duration, for the 6 year olds with conventional toys when using the robot compared to without it. This might have occurred because is not uncommon for older children to demonstrate functional play (Fein, 1981), especially if they are exploring a novel object, like the robot.

There was no significant difference between the robot and no robot conditions in terms of diversity or duration for the 5, 6 or 7 year olds (with the exception of the 6 year olds for duration) neither with conventional toys nor with unstructured materials. By the age of five, children are able to demonstrate the robotic skills of cause and effect, inhibition, laterality and sequencing (Poletz, et al., 2010; Encarnação, et al., 2014). These skills might have made it easier for the older children to perform pretend play with the robot, whereas, younger children who had not yet acquired these skills might have resorted to functional play.

The developed free-play robot set-ups have the potential to elicit the expected developmental sequence of more functional play for younger children and more pretend play for older children when measuring diversity of play. Having unstructured materials better elicited a trend in pretend play than the conventional toys. Performing more studies with typically developing children could provide a database of the play types exhibited by typically developing children at different ages when they use a robot. When children with disabilities use the robot in future studies, comparing their performance to that of the typically developing children could give a proxy measure of their play level developmental age. A trend was especially apparent when the robot was introduced, possibly due to the skills needed to control the robot. Children at a younger cognitive age might be able to build robotic skills with time and practice. Plus, there may be some parts of the task that a robot can take over, thus reducing the cognitive demand on the child. For example, when the robot is near an object, it can use vision and other sensors to automatically grasp the object. This type of assistance might allow the child to focus on the play activity, rather than robot control.

The third research question examined the play schemes the typically developing children performed. These schemes can be used to inform future development of robotic play activities to encourage pretend play for children with disabilities. The schemes in which children engaged were influenced by the kinds of toys they had. With conventional toys, without or with the robot, children performed schemes related to animals like pretending they were in a zoo, feeding the animals, or that the animals or humans were dying. In future studies, providing children with disabilities with a robot and a set of toys with an obvious scheme may be helpful to encourage pretend play.

With unstructured materials, children performed functional play like building structures, and would then sometimes perform pretend play labelling these structures and doing object substitution. With the robot, children could no longer build, so they resorted to arranging toys around the play area. Children with disabilities might perform pretend play more easily with unstructured materials if a robot could provide a means to build structures, for instance, a robotic 
arm. It is also possible that the 3-minute time frame did not give children enough time to become familiar with the robot and then move on to labelling and substituting objects. Thus, ample time might be beneficial to children with disabilities. Some children did do pretend play with unstructured materials while using the robot. Blocks and rocks elicited the most pretend play schemes when children imagined they were animals or people. A box elicited pretend play when children pretended it was a home or building. Children with disabilities who use a robot for play could benefit from having these materials available.

For the most part, the play schemes performed by younger children were oftentimes performed by older children also; however, there are schemes that only older children performed (Figure 3). The observed schemes may aid occupational therapy practitioners in selecting age appropriate schemes and materials to promote pretend play for children with disabilities.

Apparently, it is not intuitively obvious to young children how to integrate a robot into play. The diversity of play schemes was reduced for younger children, especially 3 year olds, when the robot was introduced. Social interactive, physical, and technical support by an adult were needed to facilitate play between a child with disabilities and a peer in another study with a mobile Lego robot (Ferm, et al., 2015). Modeling how to do pretend play with the robot may be useful in occupational therapy sessions, especially for 3 year olds, to increase the diversity of pretend play schemes when children use the robot.

There were limitations in the study. The cross over design may have resulted in practice carryover effects in which children may have learned to use the robot during the first conditions to which they were exposed and therefore were more accurate for the next conditions. On the other hand, children may have become tired throughout the session and showed less interest in play towards the end of the session. Randomization was done to counter these effects. Although this study was intended to be exploratory, another limitation of this study was the small sample size for each age group. Visual examination of Table 1 shows that the amount of pretend play consistently decreased when children used the robot. A larger population might have resulted in different significant statistical results. Finally, typically developing children are accustomed to direct manipulation, and robot manipulation might have interfered with their play. Results may differ when the play is performed by children with disabilities.

\section{Conclusions}

Children in all age groups were able to engage in free-play at different levels of sophistication. In general, there was a trend where younger children did more functional play and older children did more pretend play. Using the robot did affect typically developing children's play making it harder to exhibit pretend play. Children require a set of skills to manipulate toys and participate in play using robots. Older children are more likely to have these skills. In addition, the types of toys and materials available to children influenced the play schemes they performed without and with the robot. The results of this study with typically developing children can help providing a database to inform a proxy measure of the developmental play level of a child with motor impairments when he or she uses a robot to access play with toys. Results can also inform future research regarding the considerations to support pretend play in children with disabilities when using assistive robots including: 1) sufficient time to explore the robot and practice the skills to 
control the robot, 2) modeling play schemes, 3) using appropriate toys and materials and 4) implementing robot functions to facilitate manipulation and reduce cognitive demands.

\section{References}

Alvarez L (2014) A robot journey into cognition: The role and implications of augmentative manipulation in child development. PhD Thesis, Faculty of Rehabilitation Science: University of Alberta, Canada.

Barton E (2010) Development of a taxonomy of pretend play for children with disabilities. Infants \& young children 23(4): 247-261.

Blanche E (2008) Play in children with cerebral palsy: Doing with-not doing to. In: Parham L and Fazio L (eds) Play in Occupational Therapy. St. Louis, MO: Mosby Elsevier, pp. 375-393.

Burghardt A (2005) The Genesis of Animal Play: Testing the Limits. M.A.: MIT Press.

Cohen D (2006) The Development of Play, $3^{\text {rd }}$ ed. New York: Routledge Taylor \& Francis Group.

Cook A, Encarnação P and Adams, K (2010) Robots: Assistive technologies for play, learning and cognitive development. Technology and Disability 22(3): 127-145.

Cook A M et al (2011) Using Lego robots to estimate cognitive ability in children who have severe physical disabilities. Disability and Rehabilitation: Assistive Technology 6(4): 338346.

Encarnação P et al (2014) Using virtual robot mediated play activities to assess cognitive skills. Disability and Rehabilitation: Assistive Technology 9(3): 231-241.

Fein G (1981) Pretend play in childhood: an integrative review. Child Development 52(4): 10951118.

Ferland F (2003) Le Modèle Ludique. Montréal: Les Presses de l'Université de Montréal 
Ferm U, Claesson B, Ottesjö C and Ericsson S (2015) Participation and enjoyment in play with a robot between children with cerebral palsy who use AAC and their peers. Augmentative and Alternative Communication 31(2): 108-123.

Henry A (2008). Assessment of play and leisure in children and adolescents. In: Parham L and Fazio L (eds) Play in Occupational Therapy. St. Louis, MO: Mosby Elsevier, pp. 95-191.

Klein T, Gelderblom G J, de Witte L and Vanstipelen S (2011) Evaluation of short term effects of the IROMEC robotic toy for children with developmental disabilities. In: IEEE International Conference on Rehabilitation Robotics, Zurich, Switzerland, 29 June - 1 July 2011, IEEE.

Knox S (1974). A play scale. In: Reilly M (ed) Play as Exploratory Learning . Beverly Hills, CA: Sage Publications, pp. 247-266.

Kronreif G et al (2007). Robot assistant "PlayROB": User trials and results. In: Proceedings of the 16th IEEE International Symposium on Robot and Human Interactive Communication, Jeju, South Corea, 26-29 August 2007, pp. 113-117.

Marti P and Iacono I (2011) Learning through play with a robot companion. In Gelderblom G J, Soede M, Adriaens L, and Miesenberger K (eds.) Everyday Technology for Independence and Care - AAATE 2011, Assistive Technology Research Series, vol. 29, Netherlands: IOS Press, pp. 526-533.

McCune-Nicolich L (1981) Toward symbolic functioning: Structure of early pretend games and parallels with language. Child Development 52(3): 785-797.

Missiuna C and Pollock N (1991) Play deprivation in children with physical disabilities: The role of the occupational therapist in preventing secondary disabilities. The American Journal of Occupational Therapy 45(10): 882-888.

Palisano R et al. (1997) Development and reliability of a system to classify gross motor function in children with cerebral palsy. Developmental Medicine and Child Neurology 39(4): 214-223. 
Pfeifer L et al. (2011) Pretend play of children with cerebral palsy. Physical and Occupational Therapy in Pediatrics 31(4): 390-402.

Piaget J (1951) Play, Dreams and Imitation. New York: Norton.

Poletz L, Encarnação P, Adams K and Cook A (2010) Robot skills and cognitive performance of preschool children. Technology and Dissability 22(3): 117-126.

Rios A, Adams K, Magill-Evans J and Cook A (2016) Playfulness in children with severe cerebral palsy when using a robot. Physical \& Occupational Therapy in Pediatrics, in press.

Robins B et al. (2012) Scenarios of robot-assisted play for children with cognitive and physical disabilities. Social Behaviour and Communication in Biological and Artificial Systems 13(2): 189-234.

Sheskin, D J (2000) Handbook of Parametric and Nonparametric Statistical Procedures, 2nd ed., Boca Raton: Chapman \& Hall/CRC.

Stagnitti K and Unsworth C (2004) The test-retest reliability of the child-initiated pretend play assessment. American Journal of Occupational Therapy58(1): 93-99.

Stagnitti K, Rodger S and Clarke J (1997) Determining gender-neutral toys for assessment of preschool children's imaginative play. Australian Occupational Therapy Journal44(3): 119131.

Takata N (1974) Play as a prescription. In: Reilly M (ed) Play as Exploratory Learning . Beverly Hills, CA: Sage Publications, pp. 209-246.

United Nations (1991) The United Nations Convention on the Rights of the Child. London: Unicef.

World Health Organization (2001) International classification of functioning, disability and health $(I C F)$. Geneva: WHO. 


\section{Figure 1}

\section{a. Conventional toys}

\section{b. Unstructured materials}

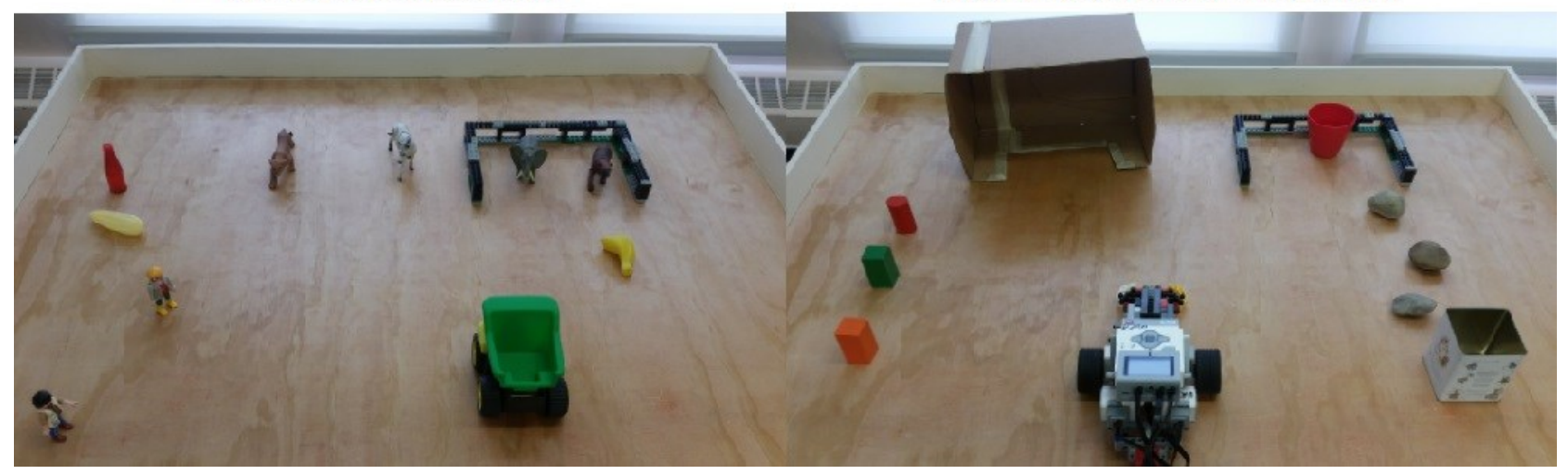

Figure 2
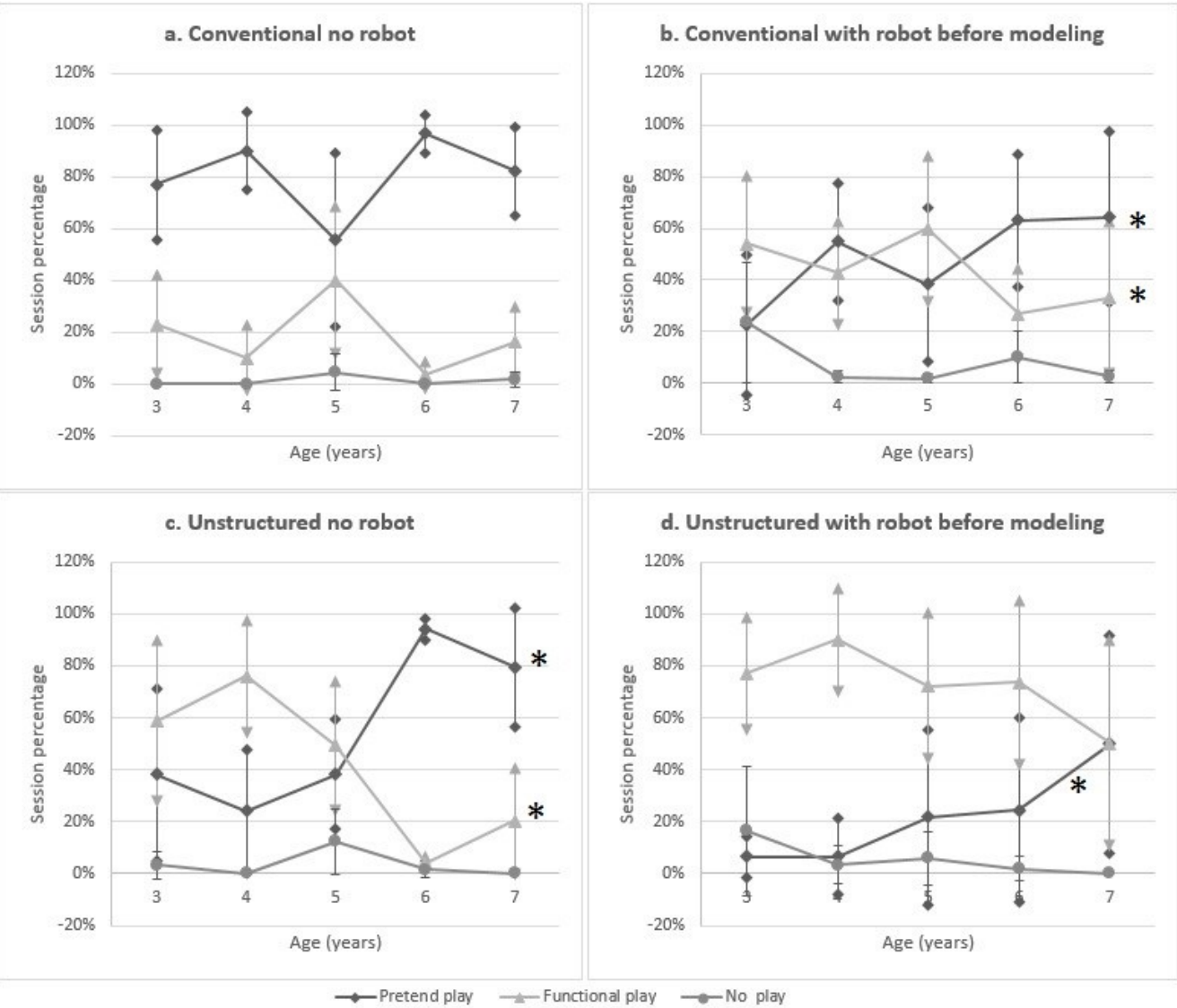
Figure 3

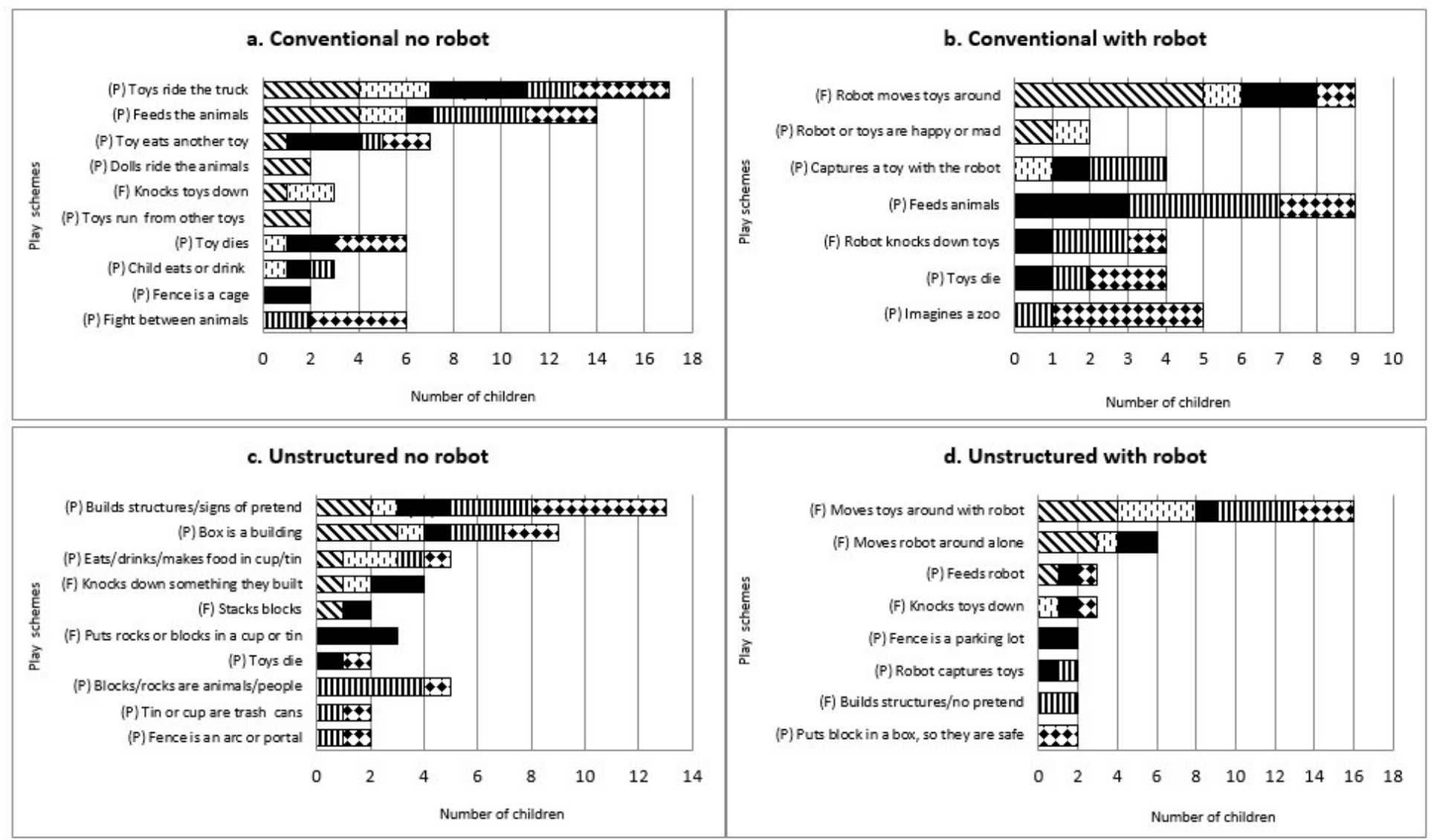

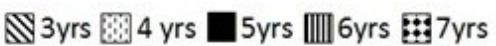


Table 1. Mean differences in the percentages of pretend and functional play between the robot (before modeling) and no robot, and between robot before modeling and robot after modeling.

\begin{tabular}{|c|c|c|c|c|c|c|c|}
\hline \multirow[t]{2}{*}{ Type of play } & \multirow[t]{2}{*}{ Toys } & \multirow{2}{*}{$\begin{array}{c}\text { Age } \\
\text { group } \\
\text { (years) }\end{array}$} & \multicolumn{2}{|c|}{$\begin{array}{c}\text { Mean difference (with robot - no } \\
\text { robot) } \pm \mathrm{SD}\end{array}$} & \multirow{2}{*}{$\begin{array}{l}\text { Number of } \\
\text { children who } \\
\text { required } \\
\text { modeling }\end{array}$} & \multicolumn{2}{|c|}{$\begin{array}{l}\text { Mean difference (after - before } \\
\text { modeling) } \pm \mathrm{SD}\end{array}$} \\
\hline & & & Diversity & Duration & & Diversity & Duration \\
\hline \multirow[t]{10}{*}{ Pretend } & \multirow[t]{5}{*}{ Conventional } & 3 & $-54 \% \pm 23 \% *$ & $-54 \% \pm 23 \% *$ & 5 & $27 \% \pm 34 \%$ & $22 \% \pm 40 \%$ \\
\hline & & 4 & $-45 \% \pm 16 \% *$ & $-25 \% \pm 26 \%$ & 3 & $-18 \% \pm 2 \%$ & $-28 \% \pm 13 \%$ \\
\hline & & 5 & $-17 \% \pm 35 \%$ & $-12 \% \pm 38 \%$ & 4 & $8 \% \pm 63 \%$ & $4 \% \pm 71 \%$ \\
\hline & & 6 & $-34 \% \pm 24 \%$ & $-38 \% \pm 37 \% *$ & 1 & $0 \% \pm 0 \%$ & $-5 \% \pm 0 \%$ \\
\hline & & 7 & $-18 \% \pm 24 \%$ & $-16 \% \pm 28 \%$ & 2 & $-4 \% \pm 87 \%$ & $10 \% \pm 106 \%$ \\
\hline & \multirow[t]{5}{*}{ Unstructured } & 3 & $-32 \% \pm 26 \% *$ & $-45 \% \pm 22 \% *$ & 7 & $6 \% \pm 17 \%$ & $-6 \% \pm 30 \%$ \\
\hline & & 4 & $-17 \% \pm 21 \%$ & $-30 \% \pm 32 \%$ & 4 & $5 \% \pm 10 \%$ & $8 \% \pm 10 \%$ \\
\hline & & 5 & $-17 \% \pm 35 \%$ & $-17 \% \pm 33 \%$ & 5 & $-3 \% \pm 35 \%$ & $0 \% \pm 36 \%$ \\
\hline & & 6 & $-64 \% \pm 39 \%$ & $-60 \% \pm 42 \%$ & 4 & $45 \% \pm 54 \%$ & $46 \% \pm 51 \%$ \\
\hline & & 7 & $-30 \% \pm 42 \%$ & $-30 \% \pm 42 \%$ & 4 & $-5 \% \pm 8 \%$ & $4 \% \pm 19 \%$ \\
\hline \multirow[t]{10}{*}{ Functional } & \multirow[t]{5}{*}{ Conventional } & 3 & $31 \% \pm 17 \% *$ & $40 \% \pm 10 \% *$ & 5 & $-15 \% \pm 26 \%$ & $-12 \% \pm 23 \%$ \\
\hline & & 4 & $33 \% \pm 14 \% *$ & $23 \% \pm 23 \%$ & 3 & $18 \% \pm 2 \%$ & $31 \% \pm 10 \%$ \\
\hline & & 5 & $20 \% \pm 30 \%$ & $14 \pm 36 \%$ & 4 & $-18 \% \pm 57 \%$ & $-18 \% \pm 57 \%$ \\
\hline & & 6 & $24 \% \pm 16 \%$ & $31 \% \pm 22 \% *$ & 1 & $0 \% \pm 0 \%$ & $5 \% \pm 0 \%$ \\
\hline & & 7 & $17 \% \pm 26 \%$ & $16 \% \pm 30 \%$ & 2 & $4 \% \pm 87 \%$ & $-10 \% \pm 106 \%$ \\
\hline & \multirow[t]{5}{*}{ Unstructured } & 3 & $18 \% \pm 39 \%$ & $50 \% \pm 19 \% *$ & 7 & $-7 \% \pm 22 \%$ & $-8 \% \pm 28 \%$ \\
\hline & & 4 & $14 \% \pm 23 \%$ & $27 \% \pm 31 \%$ & 4 & $-16 \% \pm 20 \%$ & $-15 \% \pm 10 \%$ \\
\hline & & 5 & $23 \% \pm 38 \%$ & $29 \% \pm 41 \%$ & 5 & $-4 \% \pm 24 \%$ & $-11 \% \pm 35 \%$ \\
\hline & & 6 & $65 \% \pm 35 \%$ & $61 \% \pm 39 \%$ & 4 & $-45 \% \pm 54$ & $-49 \% \pm 49 \%$ \\
\hline & & 7 & $30 \% \pm 42 \%$ & $30 \% \pm 42 \%$ & 4 & $5 \% \pm 8 \%$ & $-4 \% \pm 19 \%$ \\
\hline
\end{tabular}

* significant differences $\mathrm{p}<0.05$ 